\title{
MONITORING SUHU PADA RUANG SERVER MENGGUNAKAN WEMOS D1 R1 BERBASIS INTERNET OF THINGS (IOT)
}

\author{
Faisal Arief Deswar', Rizky Pradana² \\ ${ }^{1}$ Teknik Informatika, Universitas Budi Luhur \\ e-mail : 1611510304@student.budiluhur.ac.id \\ ${ }^{2}$ Teknik Informatika, Universitas Budi Luhur \\ e-mail : rizky.pradana@budiluhur.ac.id
}

\begin{abstract}
Abstrak
Server sangat berperan penting dalam mengelola data dan mengatur jaringan dalam sebuah perusahan. Selama ini yang kebanyakan terjadi dalam pengaturan suhu AC hanya menggunakan remote control Masalah yang muncul dalam mengontrol dan memonitoring suhu ada pada staff, dikarenakan mereka harus ada didalam ruang server untuk mengontrol dan memonitoring suhu ruangan tersebut. Mengatasi masalah tersebut penulis membuat sebuah sistem untuk mengontrol dan memonitoring suhu ruangan server agar tidak menyulitkan staff untuk melakukan set ulang dan bisa dikontrol dari jauh dengan membuat sistem yang menggunakan mikrokontroler Wemos D1 R1, sensor suhu DHT11, IR Transmitter dan LCD serta membuat aplikasi android. Metode yang digunakan yaitu prototype. Pada metode ini terdapat beberapa tahapan yaitu mengumpulkan suatu informasi dari staff, merancang dan membuat prototype dan uji coba dengan menggunakan black box testing. Hasil pengujian dari sistem tersebut adalah mikrokontroler Wemos D1 R1 dapat mengendalikan alat, mengirim dan menyimpan data suhu ke database, sensor suhu DHT11 dapat mendekteksi suhu ruangan, dan IR Transmitter dapat mengirim sinyal untuk mengontrol Air Conditioner (AC). Kesimpulannya adalah sistem dapat mengontrol suhu ruang server, sistem dapat menyimpan temperature AC dan ruangan kedalam database, sistem dapat menampilkan data temperature kedalam aplikasi android dan dapat menampilkan ke LCD.
\end{abstract}

\section{Keywords : Mikrokontroler, Wemos D1 R1, DHT11, Android, Monitoring Suhu}

\section{PENDAHULUAN}

Semakin berkembangnya teknologi komputer khususnya pada bidang elektronika, manusia selalu berusaha untuk memanfaatkan teknologi untuk mempermudah kegiatan seharihari. Salah satunya dalam pengaturan suhu AC (Air Conditioner) pada ruang server dan pemanfaatan teknologi android untuk mengontrol serta memonitoring suhu ruangan. Server sangat berperan penting dalam mengelola data dan mengatur jaringan dalam sebuah perusahan (Siswanto, Gata and Tanjung, 2017). Selama ini yang kebanyakan terjadi dalam pengaturan suhu AC hanya menggunakan remote control (Khoswanto, Pasila and Cahyadi, 2003). Keadaan ini akan sangat menyulitkan staff jika setiap kali ada perubahan temperature yang harus diset ulang melalui remote control AC (Fauzi and Mukhtar, 2016). Oleh karena itu dibutuhkan suatu inovasi baru agar AC dapat dijalankan secara otomatis dengan software Android, mikrokontroler Wemos D1 R1, sensor suhu DHT11, IR Transmitter dan LCD I2C/IIC.
Android adalah sistem operasi yang dirancang oleh Google dengan basis Operating System (OS) Linux, Graphical User Interface (GUI), web browser, aplikasi end-user untuk mendukung kinerja perangkat elektronik layar sentuh. Pemanfaatan teknologi android ini digunakan untuk mengontrol dan memonitoring suhu ruangan (Sawita, Supardi and Putra Adnyana, 2017). Mikrokontroler adalah sebuah perangkat komputasi kecil yang terdiri dari sebuah IC dengan microprocessor, Read Only Memory (ROM) dan Random Access Memory (RAM) yang dapat mengatur input/output dari alat lain (Wijanarko and Hasanah, 2017). Mikrokontroler Wemos D1 R1 sudah berbasis ESP8266 yaitu modul Wifi, CH340 USB to serial interface dan selain itu mikrokontroler ini juga sudah kompatibel dengan beragam Arduino shield (Supegina and Setiawan, 2017). Sistem ini juga berbasis konsep Internet of Things (IoT), pada sistem ini berfungsi untuk pengiriman data antar perangkat menggunakan jaringan internet (Partamayasa, Suhartana and Supriana, 2019). Masalah yang muncul dalam mengontrol dan 
memonitoring suhu ada pada staff, dikarenakan mereka harus ada didalam ruang server untuk mengontrol dan memonitoring suhu ruangan tersebut (Gunawan and Fatimah, 2020). Mengontrol dan memonitoring suhu adalah suatu hal yang cukup penting untuk dilakukan (Permana and Herawati, 2018) dan suhu merupakan hal yang berperngaruh pada server, yang dimana kestabilan suhu harus dijaga agar server tidak akan cepat rusak jika terjadi peningkatan suhu (Suherman, Andriyanto and Dwiyatno, 2015).

Tujuan penggunaan sistem ini di dalam ruang server yaitu untuk mengontrol suhu, monitoring suhu pada ruang server secara otomatis agar tidak menyulitkan staff untuk melakukan set ulang. Alat akan memberikan perintah kepada AC menaikkan atau menurunkan suhu ruang server secara otomatis sesuai dengan suhu yang akan diset kemudian data suhu akan disimpan ke database dan ditampilkan ke aplikasi android.

\section{STUDI LITERATUR}

Penelitian ini mengacu pada pembahasan yang telah dilakukan oleh peneliti sebelumnya, yaitu :

1. Penelitian yang dilakukan oleh (Widiastuti and Susanto, 2014) menjelaskan bahwa monitoring dapat difisinikaan sebagai adalah proses pengumpulan informasi yang ditetapkan secara sistematis dan berkelanjutan sehingga dapat melakukan untuk penyempurnaan.

2. Penelitian yang dilakukan oleh (Supu et al., 2016) menjelaskan bahwa suhu merupakan ukuran derajat $\left(^{\circ}\right)$ dari panas atau dingin dari suatu benda atau sistem. Suhu didefinisikan sebagai suatu besaran fisika yang memiliki dua atau lebih dari suatu benda panas lalu biasanya dinyatakan dalam skala Celcius (C), Reamur (R) dan Fahrenheit (F).

3. Penilitian yang dilakukan oleh (Partamayasa,

Suhartana and Supriana, 2019) dan (Gunawan and Fatimah, 2020) mereka menggunakan mikrokontroler Arduino Mega, NodeMCU, sensor DHT11, dan IR Transmitter. Sensor suhu mengirimkan data melalui mikrokontroler, kemudian mikrokontroler memberikan perintah kepada IR Transmitter untuk mengontrol suhu AC. Data yang diterima akan disimpan kedalam database dan ditampilkan ke dalam website.

4. Penilitian yang dilakukan oleh (Siswanto, Gata and Tanjung, 2017), (Wijanarko and
Hasanah, 2017), (Permana and Herawati, 2018) dan (Suherman, Andriyanto and Dwiyatno, 2015) mereka menggunakan mikrokontroler Arduino Uno R3, untuk alat sensor suhunya mereka menggunakan DHT22, SHT11 dan LM35. Sensor suhu mengirimkan data suhu melalui mikrokontroler, data yang diterima akan disimpan kedalam database lalu ditampilkan melalui e-mail, SMS dan website.

\section{METODE PENELITIAN}

\subsection{Metode Prototype}

Metode yang digunakan yaitu prototype. Prototype adalah suatu model/metode dalam pengembangan sistem yang menggunakan pendekatan untuk membuat sesuatu aplikasi dengan cepat dan bertahap sehingga dapat di evaluasi oleh pemakai. Pada metode ini terdapat beberapa tahapan yang meliputi:

1. Pengumpulan Informasi

Mengumpulkan suatu informasi dari staff IT mengenai permasalahan tentang sistem yang berjalan di ruang server

2. Merancang dan Membuat Prototype

Prototype yang dibuat disesuaikan dengan kebutuhan sistem yang telah didefinisikan sebelumnya dari keluhan staff

3. Uji Coba

Uji coba yang dilakukan penulis menggunakan black box testing. Pada tahap ini staff menguji coba sistem yang sudah dibuat, kemudian melakukan evaluasi dari sistem tersebut.

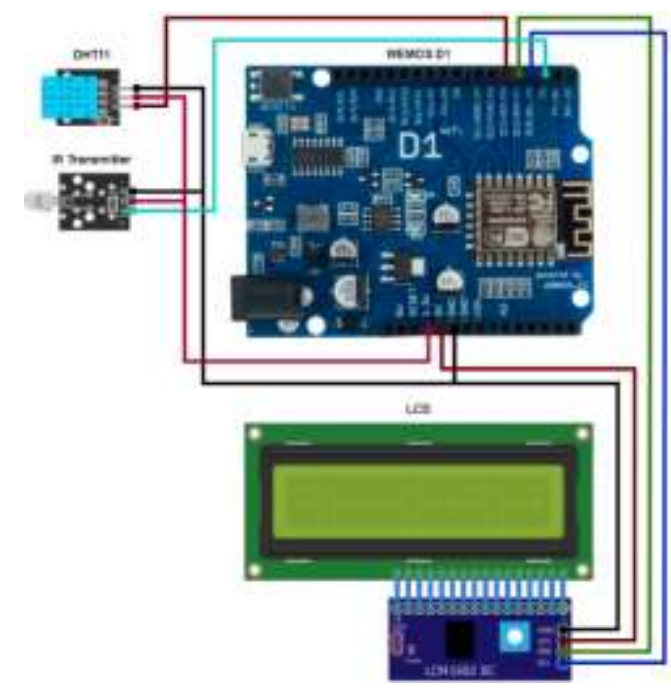

Gambar 5.

Perancangan Perangkat Keras (Hardware) 
Pada gambar 5 merupakan perancangan perangkat keras (hardware). Mikrokontroler Wemos D1 R1 ditunjukan sebagai kontrol utama, sensor DHT11 sebagai pendeteksi suhu disekitar ruangan, IR Transmitter yang berfungsi sebagai pengirim sinyal infra red kepada AC, dan LCD dengan modul I2C yang nantinya akan menampilkan keterangan suhu.

\subsection{Komponen}

\section{A. Wemos D1 R1}

Wemos D1 R1 merupakan board yang menggunakan ESP8266 sebagai modul Wifi dan dirancang menyerupai Arduino Uno. Kelebihan dari Wemos D1 R1 ini adalah bersifat open source, kompatibel dengan Arduino, dapat deprogram menggunakan Arduino IDE, pinout yang kompatibel dengan Arduino Uno, dapat berdiri sendiri tanpa menggunakan mikrokontroler lain, memiliki prosesor 32-bit dengan kecepatan
$80 \mathrm{MHz}$, High Level Language, bisa deprogram dengan bahasa pemograman Phyton dan Lua (Rianto, 2020).

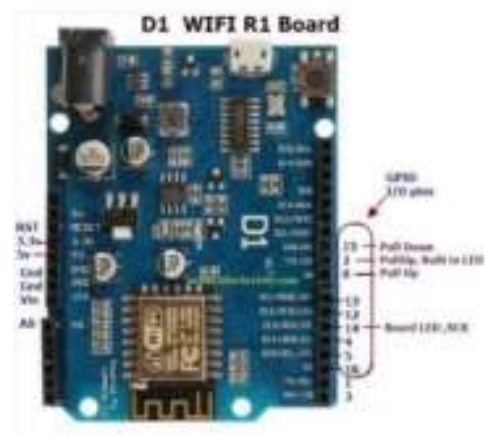

Gambar 1. Wemos D1 R1

Adapun spesifikasi dari gambar 1 mikrokontroler Wemos D1 R1 dapat ditunjukan ditabel 1:

Tabel 1. Spesifikasi Wemos D1 R1

\begin{tabular}{cll}
\hline No & \multicolumn{1}{c}{ Kategori } & \multicolumn{1}{c}{ Spesifikasi } \\
\hline 1 & Microcontroller & ESP8266 Tensilica 32-bit \\
2 & Serial to USB Converter & CH340G \\
3 & Operating Voltage & $3.3-5 \mathrm{~V}$ \\
4 & Input Voltage & $7-12 \mathrm{~V}$ \\
5 & Digital I/O Pins & 11 \\
6 & PWM I/O Pins & 10 \\
7 & Anolog Input Pins & 1 (10-bit) \\
8 & DC Current per I/O Pin & $12 \mathrm{~mA} \mathrm{(Max)}$ \\
9 & Hardware Serial Ports & 1 \\
10 & Flash Memory & 4 Mbytes \\
11 & Instruction RAM & 64 Kbytes \\
12 & Data RAM & 96 Kbytes \\
13 & Clock Speed & $80 \mathrm{MHz}$ \\
14 & Network & IEEE 802.11 b/g/n WiFi \\
15 & Built-in LED & Attached to digital pin 13 \\
16 & USB Connector Style & Micro-B Female \\
17 & Board Dimensions (PCB) & $69 \times$ x 53mm $(2.7 \times 2.1 ")$ \\
18 & Datasheet & ESP8266EX \\
\hline
\end{tabular}

\section{B. Sensor DHT11}

Sensor DHT11 adalah modul sensor yang berfungsi untuk mendeteksi objek suhu dan kelembaban yang memiliki output tegangan analog yang dapat diolah lebih lanjut menggunakan mikrokontroler. Sensor DHT11 ini mempunyai teknik pendeteksian sinyal digital yang baik pada suhu dan kelembaban, sensor ini dapat diandalkan dan memiliki kestabilan jangka panjang (Juliasari, Hartanto and Mulyati, 2016).
Sensor DHT11 ini mempunyai 3 kaki pin yang dimana pin VCC antara 3 volt - 5 volt, pin data keluaran dan pin GND atau Ground.

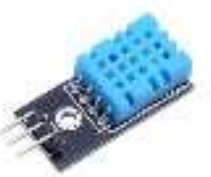

Gambar 2. Sensor DHT11 


\section{IR Transmitter}

IR Transmitter adalah komponen elektronika yang dapat mengidentifikasi cahaya infra red, yang dibuat khusus dalam satu modul sebagai IR Detector Photomodules. IR Detector Photomodules merupakan chip detector infra red digital dan didalamnya terdapat fotodiode dan amplifer. Pada transmitter dibangun dari sebuah LED infra red dan jika dibandingkan dengan LED biasa, LED infra red ini memiliki sinyal yang tampak (Rumagit et al., 2012). IR Transmitter ini mempunyai 3 kaki pin yang dimana pin GND atau Ground, pin VCC antara 3 volt -5 volt dan pin data keluaran.

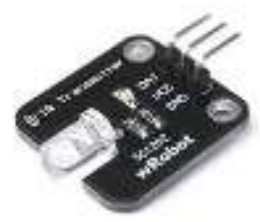

Gambar 3. IR Transmitter

\section{LCD I2C/IIC}

LCD I2C adalah Modul LCD (Liquid Crystal Display) yang dikendalikan secara serial sinkron dengan menggunakan protokol I2C/IIC (Inter Integrated Circuit) atau TWI (Two Wire Interface). Normalnya, modul LCD dikendalikan secara paralel baik untuk jalur data maupun kontrolnya. LCD ini dapat berfungsi untuk menampilkan sesuatu berupa teks atau angka yang sudah di program dari mikrokontroler (Veronika Simbar and Syahrin, 2017). LCD I2C/IIC ini mempunyai 4 kaki pin, yaitu pin GND atau Ground, pin VCC 5 volt, pin kontrol SCL dan pin kontrol SDA.

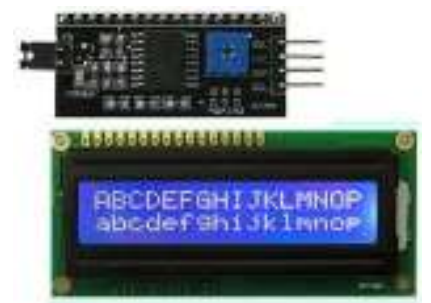

Gambar 4. LCD I2C/IIC

\section{HASIL DAN PEMBAHASAN}

\subsection{Hasil Penelitian}

Berikut adalah hasil dari penelitian sistem pengaturan suhu ruang server menggunakan sensor DHT11 berbasis mikrokontroler Wemos
D1 R1. Penelitian ini dapat dilihat pada gambar dibawah ini.

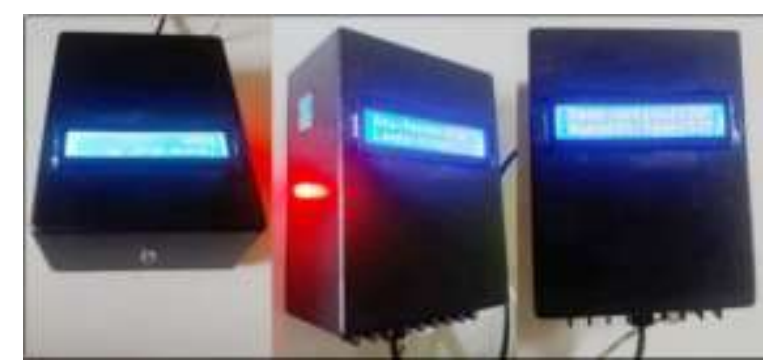

Gambar 6. Rangkaian Hardware

Pada gambar 6 diatas adalah rangkaian hardware mikrokontroler yang diletakan didalam kotak hitam, modul LCD didtempatkan didepan, sensor DHT11 diletakan disamping dan IR Transmitter diletakan di atas kotak.

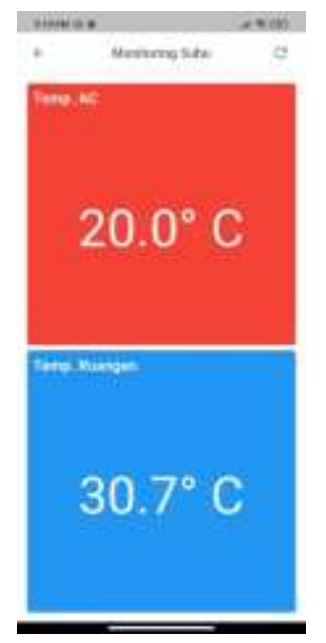

Gambar 7.

Tampilan Interface Monitoring Suhu

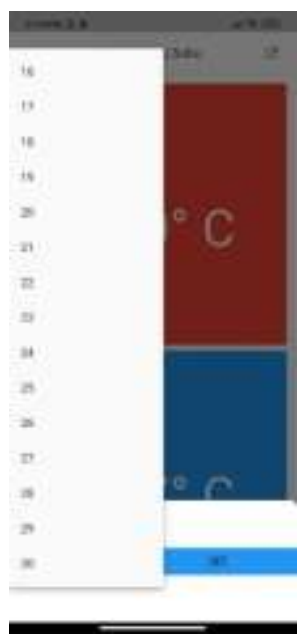

Gambar 8.

Tampilan Interface

Set Temprature
Pada gambar 7 menujukan informasi tentang status suhu ac dan ruangan pada ruang server yang sudah tersimpan didalam database. Pada Gambar 8 menunjukan tampilan Set Temperature yang dimana berfungsi untuk mengirim suhu yang diinginkan dari $16^{\circ} \mathrm{C}-30^{\circ} \mathrm{C}$ ke AC tersebut.

\subsection{Pengujian}

Pada tahap ini bertujuan untuk menguji sistem yang telah dibuat oleh peneliti serta mengetahui kesalahan dari sistem tersebut. Berikut adalah tahap - tahap pengujian dengan menggunakan metode Black Box : 
Tabel 2. Pengujian Black Box Mikrokontroler Wemos D1 R1

\begin{tabular}{|c|c|c|c|c|}
\hline No & Uji Coba & Kondisi & Hasil Yang Diharapkan & Hasil \\
\hline 1 & & Terhubung dengan Wifi & $\begin{array}{l}\text { Menampilkan keterangan } \\
\text { "Wifi has Connected" }\end{array}$ & $\checkmark$ \\
\hline 2 & & $\begin{array}{l}\text { Tidak Terhubung dengan } \\
\text { Wifi }\end{array}$ & $\begin{array}{l}\text { Menampilkan keterangan } \\
\text { "Wifi is Connecting" }\end{array}$ & $\checkmark$ \\
\hline 3 & & $\begin{array}{c}\text { Terhubung dengan Server } \\
\text { Heroku }\end{array}$ & $\begin{array}{l}\text { Menampilkan keterangan } \\
\text { "Heroku has Connected" }\end{array}$ & $\checkmark$ \\
\hline 4 & $\begin{array}{l}\text { Mikrokontroler } \\
\text { Wemos D1 R1 }\end{array}$ & $\begin{array}{c}\text { TidakTerhubung dengan } \\
\text { Server Heroku }\end{array}$ & $\begin{array}{l}\text { Menampilkan keterangan } \\
\text { "Heroku is Connecting" }\end{array}$ & $\checkmark$ \\
\hline 5 & & $\begin{array}{c}\text { Berhasil Mengirimkan } \\
\text { Data Temperature AC ke } \\
\text { Database }\end{array}$ & $\begin{array}{l}\text { Menampilkan keterangan } \\
\text { "Memperbarui" }\end{array}$ & $\checkmark$ \\
\hline 6 & & $\begin{array}{c}\text { Tidak Berhasil } \\
\text { Mengirimkan Data } \\
\text { Temperature AC ke } \\
\text { Database }\end{array}$ & $\begin{array}{l}\text { Menampilkan keterangan } \\
\text { "Gagal Memperbarui" }\end{array}$ & $\checkmark$ \\
\hline
\end{tabular}

Keterangan : Dari tahap uji coba pada tabel 2 dapat diketahui bahwa:

a. LCD akan menampilkan tulisan Wifi has Connected apabila Wemos D1 R1 dapat terhubung ke Wifi, dan apabila Wemos D1 R1 tidak dapat terhubung ke Wifi maka LCD akan menampilkan tulisan Wifi is Connecting.

b. LCD akan menampilkan tulisan Heroku has Connected apabila Wemos D1 R1 dapat terbuhung ke server Heroku, dan apabila Wemos D1 R1 tidak dapat terhubung ke server Heroku maka LCD akan menampilkan tulisan Heroku is Connecting.

c. LCD akan menampilkan tulisan Memperbarui apabila Wemos D1 R1 dapat mengirim data temperature AC ke database, dan apabila Wemos D1 R1 tidak dapat mengirimkan data tersebut maka LCD akan menampilkan tulisan Gagal Memperbarui.

Tabel 3. Pengujian Black Box Sensor Suhu DHT11

\begin{tabular}{ccccc}
\hline No & Uji Coba & Kondisi & Hasil Yang Diharapkan & Hasil \\
\hline 1 & & $\begin{array}{c}\text { Didekatkan dengan benda } \\
\text { panas }\end{array}$ & $\begin{array}{c}\text { Output temperature bernilai } \\
\text { tinggi }\end{array}$ & $\checkmark$ \\
2 & Sensor DHT11 & $\begin{array}{c}\text { Diletakan diruangan } \\
\text { berAC }\end{array}$ & $\begin{array}{c}\text { Output temperature bernilai } \\
\text { rendah }\end{array}$ & $\checkmark$ \\
\hline
\end{tabular}

Keterangan : Dari tahap uji coba pada tabel 3 dapat diketahui bahwa sensor DHT11 jika didekatkan dengan benda yang bersuhu panas maka outputnya akan bernilai tinggi dan jika diletetakan diruangan yang bersuhu dingin atau berAC makan outputnya akan bernilai rendah. 
Tabel 4. Pengujian Black Box IR Transmitter

\begin{tabular}{ccccc}
\hline No & Uji Coba & Jarak & Hasil Yang Diharapkan & Hasil \\
\hline 1 & & $<450 \mathrm{~cm}$ & Dapat Mengirim Data & $\checkmark$ \\
& IR Transmitter & $>450 \mathrm{~cm}$ & Tidak Dapat Mengirim Data & $\checkmark$ \\
\hline
\end{tabular}

Keterangan : Dari tahap uji coba pada tabel 4 dapat diketahui bahwa pada jarak di atas $420 \mathrm{~cm} \mathrm{IR}$ Transmitter tidak dapat mengirimkan data

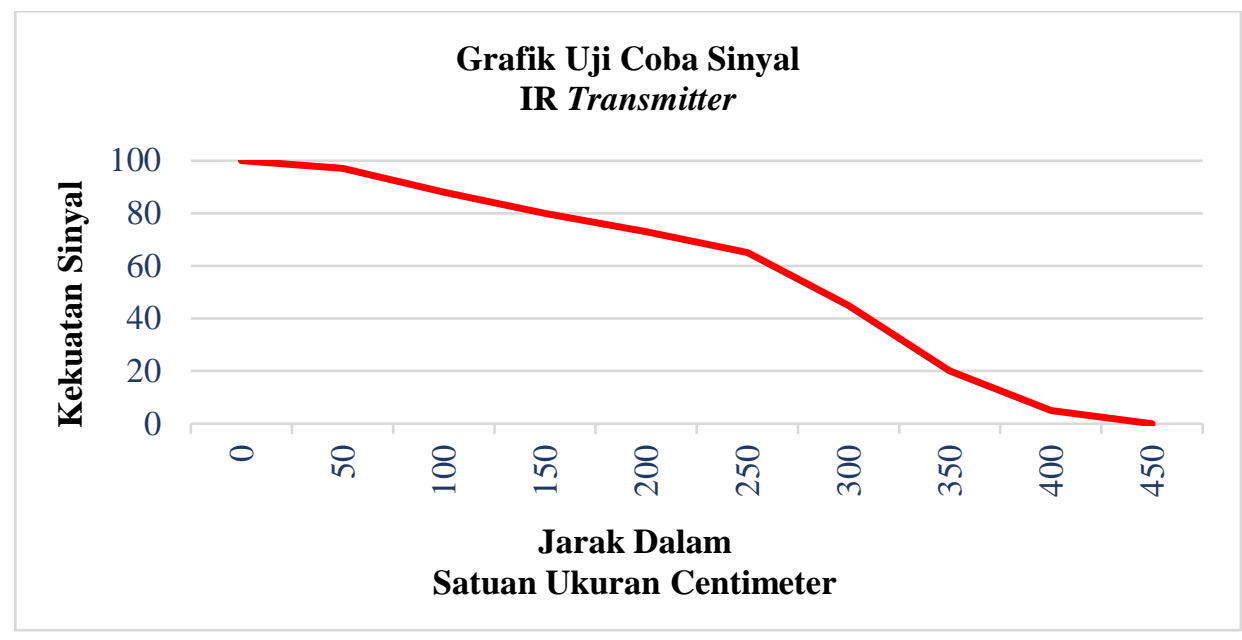

Gambar 9. Grafik Uji Coba Sinyal IR Transmitter

Keterangan: Pada gambar 9 dapat diketahui bahwa dalam jarak $0 \mathrm{~cm}-250 \mathrm{~cm}$ sinyal yang dikirim oleh IR Transmitter ke AC sangat baik, dalam jarak 250 - $400 \mathrm{~cm}$ sinyal yang dikirim dari IR Transmitter sudah mulai kurang baik dan pada jarak $450 \mathrm{~cm}$ keatas IR Transmitter sudah tidak bisa menggirim sinyal.

\subsection{Pembahasan}

Berdasakan dari hasil yang sudah dibahas sebelumnya, implementasi dari sistem pengaturan suhu ruang server menggunakan sensor DHT11 yang berbasis mikrokontroler Wemos D1 R1. Dalam pembuatan sistem ini, menerapkan metode prototype yang mana memiliki beberapa tahapan, diantaranya : mengumpulkan suatu informasi dari staff IT mengenai permasalahan tentang sistem yang berjalan di ruang server, merancang dan membuat prototype, staff IT menyesesuaikan dengan kebutuhan sistem yang telah didefinisikan sebelumnya dari keluhan staff menguji coba prototype dengan menggunakan metode uji coba Black Box, staff menguji coba sistem ini dan mengevaluasi sistem tersebut.

Dari hasil pembuatan sistem diatas mendapatkan hasil bahwa sistem dapat mengontrol suhu dan memonitoring suhu pada ruang server dengan baik. Hasil pengujian dapat diketahui bahwa sensor DHT11 dapat mendeteksi suhu bernilai tinggi apabila sensor didekatkan dengan benda yang bersuhu panas, dan suhu akan bernilai rendah apabila diletakkan diruangan yang bersuhu dingin atau berAC. Selanjutnya tahap pengujian IR Transmitter, IR Transmitter akan berhasil mengirimkan data dengan jarak dibawah $420 \mathrm{~cm}$ dalam penelitian yaitu pengiriman perintah dari mikrokontroler Wemos D1 R1 ke AC untuk pengontrolan suhu ruang server dan apabila jarak IR Transmitter dengan AC diatas $420 \mathrm{~cm}$ maka AC tidak dapat menerima perintah dari sistem. Pada tahap pengujian LCD dari mikrokontroler mendapatkan hasil tampilan sebagai berikut : LCD akan menampilkan tulisan Wifi has Connected ketika mikrokontroler Wemos 
D1 R1 terhubung dengan Wifi, dan apabila tidak terhubung dengan Wifi maka LCD akan menampilkan tulisan Wifi is Connecting. LCD akan menampilkan tulisan Heroku has Connected ketika mikrokontroler Wemos D1 R1 terkoneksi ke server Heroku dan apabila tidak terhubung dengan server Heroku maka LCD akan menampilkan tulisan Heroku is Connecting. Terakhir LCD akan menampilkan tulisan Memperbarui apabila Wemos D1 R1 dapat mengirim data temperature AC ke database dan apabila Wemos D1 R1 tidak dapat mengirimkan data tersebut maka LCD akan menampilkan tulisan Gagal Memperbarui.

\section{KESIMPULAN}

Berdasarkan penelitian implementasi dari sistem pengaturan suhu ruang server menggunakan sensor DHT11 berbasis mikrokontroler Wemos D1 R1 dapat disimpulkan bahwa :

1) Sistem dapat mengontrol suhu ruang server dengan memberi perintah dari mikrokontroler Wemos D1 R1 ke IR Transmitter untuk menaikan dan menurunkan Temperature AC secara otomatis yang disesuaikan dari aplikasi android yang telah dibuat.

2) Sistem dapat menyimpan Temperature AC dan Ruangan kedalam database.

3) Sistem dapat menampilkan data Temperature kedalam aplikasi android yang terhubung dengan internet dan juga dapat menampilkan ke LCD yang sudah terpasang pada mikrokontroler.

\section{REFERENSI}

[1] Fauzi, M. R. and Mukhtar, H. (2016) 'Rancang Bangun Sistem Pengaturan Temperatur Ruangan Menggunakan Sensor DHT11 Berbasis Mikrokontroler Arduino', PROSIDING 1th Celscitech-UMRI, 1, pp. 122-126.

[2] Gunawan, G. and Fatimah, T. (2020) 'Implementasi Sistem Pengaturan Suhu Ruang Server Menggunakan Sensor DHT11 dan Sensor PIR Berbasis Mikrokontroler', Edumatic: Jurnal Pendidikan Informatika, 4(1), pp. 101-110. doi: 10.29408/edumatic.v4i1.2165.

[3] Juliasari, N., Hartanto, E. D. and Mulyati, S. (2016) 'Monitoring Suhu dan Kelembaban pada Mesin Pembentukan Embrio Telur Ayam Berbasis Mikrokontroler Arduino
UNO', Jurnal TICOM, 4(3), pp. 109-113. Available at: https://media.neliti.com/media/publications/ 92893-ID-monitoring-suhu-dankelembaban-pada-mesi.pdf.

[4] Khoswanto, H., Pasila, F. and Cahyadi, W. E. (2003) 'SISTEM PENGATURAN AC OTOMATIS', Perancangan Dan Realisasi Sistem Pengatur Suhu Ac Otomatis Berbasis Mikrokontroler, pp. 73-78.

[5] Partamayasa, I. W. G., Suhartana, I. K. G. and Supriana, I. W. (2019) 'Perancangan Sistem Pengaturan Suhu Ruangan Otomatis Berbasis Mikrokontroler', Jurnal Elektronik Ilmu Komputer Udayana, 08(01), pp. 95-104.

[6] Permana, E. and Herawati, S. (2018) 'RANCANG BANGUN SISTEM MONITORING SUHU RUANGAN BAGIAN PEMBUKUAN BERBASIS WEB MEGGUNAKAN MIKROKONTROLER ARDUINO UNO R3', Jurnal Teknologi Informasi dan Komunikasi STMIK Subang, (April), pp. 18-33.

[7] Rianto, Y. (2020) 'Mendekteksi gerakan kamera menggunakan wemos $\mathrm{d} 1 \mathrm{r} 1$ berbasis iot', (100), pp. 1-28.

[8] Rumagit, F. D. et al. (2012) 'Perancangan Sistem Switching 16 Lampu Secara Nirkabel Menggunakan Remote Control', E-Journal Teknik Elektro Dan Komputer, 1(2), pp. 1-5.

[9] Sawita, I. K. A. S., Supardi, I. W. and Putra Adnyana, I. G. A. (2017) 'Alat Monitoring Suhu Melalui Aplikasi Android Menggunakan Sensor LM35 dan Modul SIM800L Berbasis Mikrokontroler ATMega16', Buletin Fisika, 18(2), p. 58. doi: 10.24843/bf.2017.v18.i02.p03.

[10] Siswanto, Gata, W. and Tanjung, R. (2017) 'Kendali Ruang Server Menggunakan Sensor Suhu DHT 22, Gerak Pir dengan Notifikasi Email', PROSIDING seminar nasional sisfotek Sistem Informasi dan Teknologi Informasi, 3584, pp. 134-142.

[11] Suherman, Andriyanto, I. and Dwiyatno, S. (2015) 'Rancang Bangun Alat Ukur Temperatur Suhu Perangkat Server Menggunakan Sensor LM35 Bebasis SMS Gateway', Jurnal Prosisko, 2(1), pp. 42-63.

[12] Supegina, F. and Setiawan, E. J. (2017) 'Rancang Bangun Iot Temperature Controller Untuk Enclosure Bts Berbasis Microcontroller Wemos Dan Android', Jurnal Teknologi Elektro, Universitas Mercu 
Buana, 8(2), pp. 145-150.

[13] Supu, I. et al. (2016) 'PENGARUH SUHU TERHADAP PERPINDAHAN PANAS PADA MATERIAL YANG BERBEDA Idawati', 07(April), pp. 62-73.

[14] Veronika Simbar, R. S. and Syahrin, A. (2017) 'Prototype Sistem Monitoring Temperatur Menggunakan Arduino Uno R3 Dengan Komunikasi Wireless', Jurnal Teknik Mesin, 5(4), p. 48. doi: 10.22441/jtm.v5i4.1225.

[15] Widiastuti, N. I. and Susanto, R. (2014) 'Kajian sistem monitoring dokumen akreditasi teknik informatika unikom', Majalah Ilmiah UNIKOM, 12(2), pp. 195202. doi: 10.34010/miu.v12i2.28.

[16] Wijanarko, D. and Hasanah, S. (2017) 'Monitoring Suhu Dan Kelembaban Menggunakan Sms Gateway Pada Proses Fermentasi Tempe Secara Otomatis Berbasis Mikrokontroler', Jurnal Informatika Polinema, 4(1), p. $49 . \quad$ doi: 10.33795/jip.v4i1.144. 